\section{A Pedigree Tracing Program for Use with DBASE III and dBASE IV Software}

\author{
Terry A. Bacon and D.H. Byrne \\ Department of Horticulture, Texas A\&M University, College Station, \\ TX 77843-2133
}

Additional index words. breeding, germplasm, software

Breeding programs maintain extensive pedigree files for genetic studies, determination of coancestry coefficients, planning crosses, and quick reference (Barr, 1983; Bell et al., 1980; Byrne, 1989; Scorza et al., 1985). This information is also used to trace pedigrees and produce graphic lineages. The tracing of a pedigree from a large file is often done by hand or with a mainframe computer (Bell et al., 1980; Scorza et al., 1985). The process, although not complex, can be cumbersome and inconvenient. There is a trend now to use microcomputers with large-capacity storage media (e.g., hard disks) that can store extensive data files. With them, researchers have the advantage of being able to interact with the computer in a more convenient and efficient manner using sophisticated, menu-driven software packages.

Researchers at the Stonefruit Breeding Program, Texas A\&M Univ., have developed a computer program named "PED" in the dBASE III/dBASE IV (Ashton-Tate Corp., Torrance, Calif.) programming language that searches a dBASE pedigree data file and quickly produces a four-generation graphic family tree (Fig. 1) on the screen or for printing (Liskin, 1986). Pedigree data are

Received for publication 26 Apr. 1990. The cost of publishing this paper was defrayed in part by the payment of page charges. Under postal regulations, this paper therefore must be hereby marked advertisement solely to indicate this fact. stored in a dBASE data file (Fig. 2). The data file structure consists of fields for a cultivar name $(\mathrm{CV})$ that is followed by the female parent (FP) and the pollen parent (PP). Records can be entered manually by the user or imported to the dBASE data file from a data file in ASCII format. The data file must have parent names of cultivars entered as cultivars in the $\mathrm{CV}$ field so that the program will work properly. When one or both of the parents are not known, the field or fields can be left blank and the program lists them as "UNKNOWN."

The user, while in dBASE, initiates the program by entering the command "DO PED." The program begins by prompting the user to choose printer or screen for output. The user is then prompted for the cultivar name. PED uses the dBASE "SEEK"

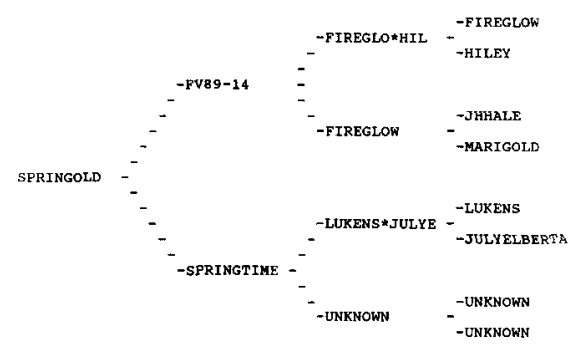

Fig. 1. An example of the family tree output produced by PED using peach pedigree file developed by Scorza et al. (1985). command to quickly locate the requested record. The program stores parent names of cultivars, then SEEKs and stores grandparents and great-grandparents. Once output is completed, PED prompts the user to choose whether to do more or return to the dBASE dot prompt. A total of four generations, including the requested individual, may be compiled, although it is possible to modify the program to accomodate larger pedigrees.

PED has proven to be a quick and convenient tool that allows the breeder more versatility and power with pedigree data. A printed copy of the program can be obtained by sending a self-addressed, stamped envelope to T.A.B.

\section{Literature Cited}

Barr, A.J. 1983. The INBREED procedure, p. 121-130. In: S.P. Joyner (ed.). SUGI supplemental library user's guide, 1983 ed. SAS Institute, Cary, N.C.

Bell, R.L., J. Janick, and R.C. Blake. 1980. Computer tracing of pedigrees. HortScience 15(3):303-304.

Byrne, D.H. 1989. Inbreeding, coancestry, and founding clones of Japanese-type plums of California and the southeastern United States. J. Amer. Soc. Hort. Sci. 114(4):699-705.

Liskin, M. 1986. Advanced dBASE III: Programming techniques. McGraw-Hill, Berkeley, Calif.

Scorza, R., S.A. Mehlenbacher, and G.W. Lightner. 1985. Inbreeding and coancestry of freestone peach cultivars of the eastern United States and implications for peach germplasm improvement. J. Amer. Soc. Hort. Sci. 110(4):547552.

\begin{tabular}{lll} 
CV & FP & PP \\
\hline SPRINGBRITE & FLA3148 & SPRINGTIME \\
SPRINGCREST & FV89-14 & SPRINGTIME \\
SPRINGOLD & FV89-14 & SPRINGTIME \\
SPRINGTIME & LUKENS*JULYE & \\
SRBM2 & SWA*RIO & BAB*MAY \\
STANFORD & HAUSS & PHILLIPSCLIN \\
STANWICKNECT & & \\
STARDUST & S5323 & \\
STARKCOMPACT & & \\
STARKEARLIGL & & \\
STARKENCORE & NJ585414 & AUTUMNGLO
\end{tabular}

Fig. 2. The structure of PEDDAT.DBF, the pedigree data file $(\mathrm{CV}=$ cultivar name; $\mathrm{FP}=$ female parent; $\mathrm{PP}=$ pollen parent). 